\title{
Copper Inhibits NMDA Receptor-Independent LTP and Modulates the Paired-Pulse Ratio after LTP in Mouse Hippocampal Slices
}

\author{
Nina L. Salazar-Weber and Jeffrey P. Smith \\ Department of Biology, Colorado State University-Pueblo, 2200 Bonforte Boulevard, Pueblo, CO 81001, USA \\ Correspondence should be addressed to Jeffrey P. Smith, jeff.smith@colostate-pueblo.edu
}

Received 2 June 2011; Revised 5 August 2011; Accepted 16 August 2011

Academic Editor: Rosanna Squitti

Copyright (C) 2011 N. L. Salazar-Weber and J. P. Smith. This is an open access article distributed under the Creative Commons Attribution License, which permits unrestricted use, distribution, and reproduction in any medium, provided the original work is properly cited.

Copper misregulation has been implicated in the pathological processes underlying deterioration of learning and memory in Alzheimer's disease and other neurodegenerative disorders. Supporting this, inhibition of long-term potentiation (LTP) by copper (II) has been well established, but the exact mechanism is poorly characterized. It is thought that an interaction between copper and postsynaptic NMDA receptors is a major part of the mechanism; however, in this study, we found that copper (II) inhibited NMDA receptor-independent LTP in the CA3 region of hippocampal slices. In addition, in the CA3 and CA1 regions, copper modulated the paired-pulse ratio (PPR) in an LTP-dependent manner. Combined, this suggests the involvement of a presynaptic mechanism in the modulation of synaptic plasticity by copper. Inhibition of the copper-dependent changes in the PPR with cyclothiazide suggested that this may involve an interaction with the presynaptic AMPA receptors that regulate neurotransmitter release.

\section{Introduction}

Copper is a trace element that plays many important roles in the brain, one of the most copper-rich organs of the body. It is an essential structural component and cofactor for many proteins and enzymes, including various effectors of synaptic plasticity, suggesting that it has an important role in regulating the cellular processes underlying learning and memory $[1,2]$. The importance of copper in learning and memory is underscored in neurodegenerative diseases including Alzheimer's, Menkes', Wilson's, and Prion disease, in which misregulation of copper is strongly associated with learning and memory deficits $[1,3-5]$. It is estimated that copper is present in the extracellular space of brain tissue at a concentration between 0.2 and $1.7 \mu \mathrm{M}$; however, it is released during neurotransmission into some glutamatergic synapses where it transiently reaches levels estimated to rise to as high as a few hundred micromolar [6-8]. Synaptically released copper may regulate synaptic plasticity by dampening NMDA, AMPA, and GABA receptor function, as each of these receptors is inhibited by copper at concentrations ranging from the low nanomolar for GABA receptors, to the low micromolar, for AMPA and NMDA receptors [914]. However, very little is currently known about the precise mechanisms by which copper interacts with the cellular processes governing learning and memory.

Doreulee et al. (1997) first reported that long-term potentiation (LTP) in the CA1 region of the rodent hippocampus is inhibited by $1 \mu \mathrm{M}$ copper (II) when present in the extracellular solution bathing slice preparations [15]. LTP, the activity-dependent strengthening of synaptic communication, is a form of synaptic plasticity that is widely accepted as a major mechanism underlying learning and memory $[16,17]$. The inhibition of LTP by copper was later repeated and was also observed in brain slices of rats after chronic ingestion or intraperitoneal injection of copper; however, the mechanism behind the inhibition has not been characterized [18-20]. Investigators have suggested that the mechanism may be NMDA receptor dependent; however, it has not yet been investigated whether inhibition of LTP by copper can occur without a contribution from NMDA receptors. It was also shown in one study using slices from the CA1 
region of the hippocampus that copper affected the pairedpulse ratio (PPR), a marker of short-term plasticity that is expressed presynaptically [18]. Therefore, in this study, we investigated the inhibition of NMDA receptor-independent LTP by copper in the CA3 region of mouse hippocampal slices. Complete inhibition was observed, and, because LTP in this region is expressed presynaptically, a presynaptic mechanism was suggested. This was further supported by our additional studies showing that the PPR was modulated by copper in both the CA3 and CA1 regions in a manner that was entirely dependent upon the expression of LTP. These results demonstrate that copper can affect presynaptic function during its modulation of hippocampal synaptic plasticity and, therefore, extends our understanding of its mechanism of action beyond a more simple model that involves only the postsynaptic machinery.

\section{Materials and Methods}

2.1. Brain Slice Preparation. Electrophysiological experiments were conducted in accordance with the Colorado State University-Pueblo Institutional Animal Care and Use Committee (IACUC) guidelines essentially as described previously [21]. Briefly, Swiss Webster mice were housed in standard conditions with 12 hours of light and 12 hours of dark. They were given unlimited access to lab chow and tap water that was filtered using a household pitcher-style filter (Brita). Males and females were used at random between the ages of 1 to 3 months. Mice were sacrificed by decapitation, and a Lancer Vibratome Series 1000 was used to make $350 \mu \mathrm{M}$ transverse brain slices through the hippocampus. The brain slices were incubated for a minimum of one hour in artificial cerebrospinal fluid (ACSF) supplemented with $2 \mathrm{mM}$ ascorbic acid before being transferred to the recording chamber. ACSF contained (in mM) $124 \mathrm{NaCl}, 2.5 \mathrm{KCl}, 2$ $\mathrm{MgSO}_{4}, 2 \mathrm{CaCl}_{2}, 10$ D-glucose, $1.25 \mathrm{NaH}_{2} \mathrm{PO}_{4}$, and 26 $\mathrm{NaHCO}_{3}$ and was bubbled vigorously with $95 \% \mathrm{O}_{2} / 5 \% \mathrm{CO}_{2}$. The $\mathrm{pH}$ was adjusted with $1 \mathrm{M} \mathrm{HCl}$ or $1 \mathrm{M} \mathrm{NaOH}$ to between 7.35 and 7.40 and was periodically monitored throughout the course of experimentation. During recording, slices were perfused with oxygenated ACSF at a rate of 3-4 mL per minute at room temperature.

2.2. Stimulation Procedure and Statistics. To measure the field excitatory postsynaptic potential (fEPSP), a $200 \mu \mathrm{M}$ diameter bipolar concentric stimulating electrode (FHC CBAEC75) and a sharp borosilicate glass recording electrode filled with $2 \mathrm{M} \mathrm{NaCl}$ were placed in the stratum radiatum of the CA1 region of the hippocampus at a $250-500 \mu \mathrm{M}$ interelectrode distance. For CA3 recording, the stimulating electrode was placed on the mossy fiber pathway, and responses were recorded in the stratum lucidum as shown in Figure 1(a). The slice was stimulated with a square pulse of $0.1 \mathrm{~ms}$ duration every 30 seconds. To determine the test stimulus intensity, a paired-pulse test was done, and the stimulus intensity was adjusted to the point at which a population spike was evoked on the second, but not the first, pulse as shown in Figure 1(b). This calibration protocol resulted in a stimulus that was $30-50 \%$ of the intensity required to elicit a max- imum response. The paired-pulse ratio (PPR) was measured at a $50 \mathrm{~ms}$ interpulse interval and calculated by dividing the slope of the second fEPSP by the first and converting the ratio to a percentage. For LTP, the baseline fEPSP was obtained for a minimum of 30 minutes, followed by four high-frequency $(100 \mathrm{~Hz})$ tetani of one-second duration which were applied in place of the test pulse with a two-minute interval between the second and third tetani. Responses were recorded for 60 minutes after the last tetanus, and the slopes of the fEPSPs were calculated using Clampfit 8 (Axon Instruments). The slopes were averaged over the last five minutes and compared between experimental groups using a paired $t$-test. For the studies with cyclothiazide (CTZ), a two-sample $t$-test was used.

2.3. Pharmacological Treatments. Interleaved experiments were conducted with ACSF alone or with $5 \mu \mathrm{M} \mathrm{CuCl}_{2}, 5 \mu \mathrm{M}$ $\mathrm{ZnCl}_{2}, 100 \mu \mathrm{M} \mathrm{CTZ}, 40 \mu \mathrm{M}$ picrotoxin, and/or $10 \mu \mathrm{M}$ MK801. All test solutions were present for the duration of the experiments and were added directly to the ACSF, except for CTZ and picrotoxin, which were dissolved in DMSO; for these experiments, DMSO was also added to the ACSF for the control slices at a final concentration of $0.1 \%$. All chemicals were purchased from Sigma, except for CTZ (A.G. Scientific, Inc.) and MK-801 (Tocris).

\section{Results}

Extracellular field potential recording was done in the CA1 and $\mathrm{CA} 3$ regions of mouse hippocampal slices with and without $5 \mu \mathrm{M} \mathrm{CuCl}_{2}$ in the recording solution for the duration of experiments. The slopes and waveforms of the fEPSPs, taken after a 30-minute baseline, were not significantly different between control and copper-treated slices in either the CA1 or CA3 regions of the hippocampus (Figures 1(c) and 1(d)). This was consistent with previous reports that $1 \mu \mathrm{M}$ copper (II) did not affect the slope of the fEPSP but that $10 \mu \mathrm{M}$ copper (II) depressed it to $85 \%$ of control [15]. Thus, $5 \mu \mathrm{M}$ copper did not appear to affect basal synaptic transmission in our experiments.

Confirming previous studies, $5 \mu \mathrm{M}$ copper (II) completely blocked LTP of the fEPSP slope in the hippocampal CA1 region of our brain slices (Figures 2(a) and 2(b)) [15, 18, 19]. Also, posttetanic potentiation (PTP) in the CA1 region, measured as the peak fEPSP slope immediately following tetanic stimulation, was somewhat reduced in the presence of copper (Figure 2(c)). LTP in this brain region was dependent on NMDA receptors as it was blocked with DAP5 (data not shown).

To test the requirement for NMDA receptors in the inhibition of LTP by copper, we repeated the above experiments by stimulating the mossy fibers and recording in the CA3 dendritic region with $10 \mu \mathrm{M}$ MK-801, an NMDA receptor inhibitor, in the bath to isolate NMDA receptor-independent LTP. We were unable to evoke a sufficient LTP to do the experiment in this region; however, with the addition of $40 \mu \mathrm{M}$ picrotoxin, a GABA receptor inhibitor, robust LTP was present one hour after tetanic stimulation in control slices, and, just as in the CA1 region, copper completely 


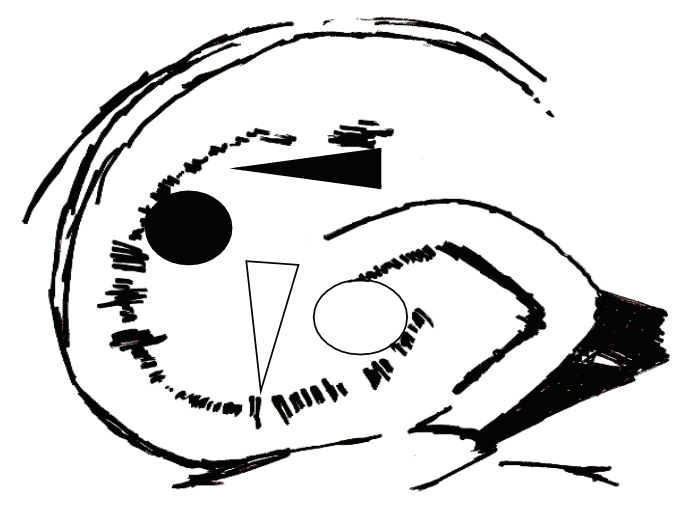

(a)

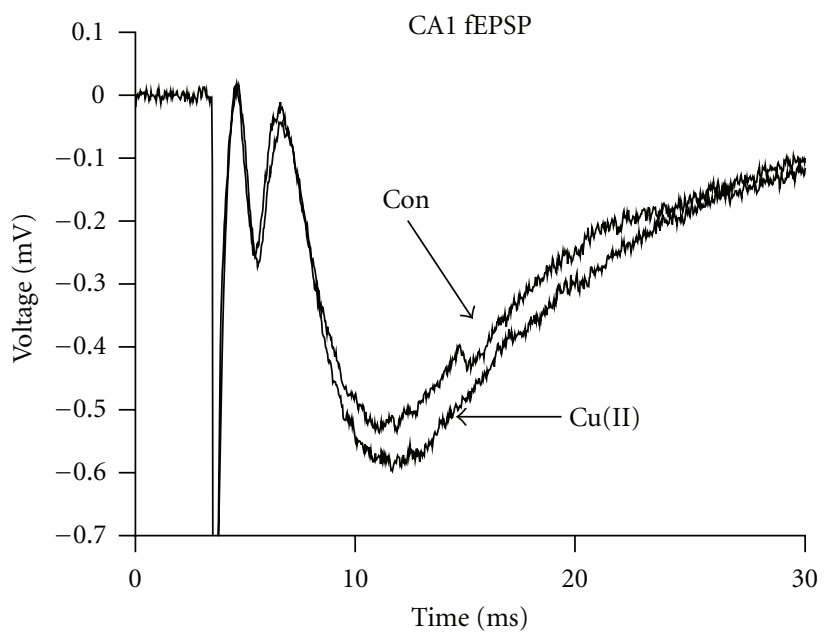

(c)

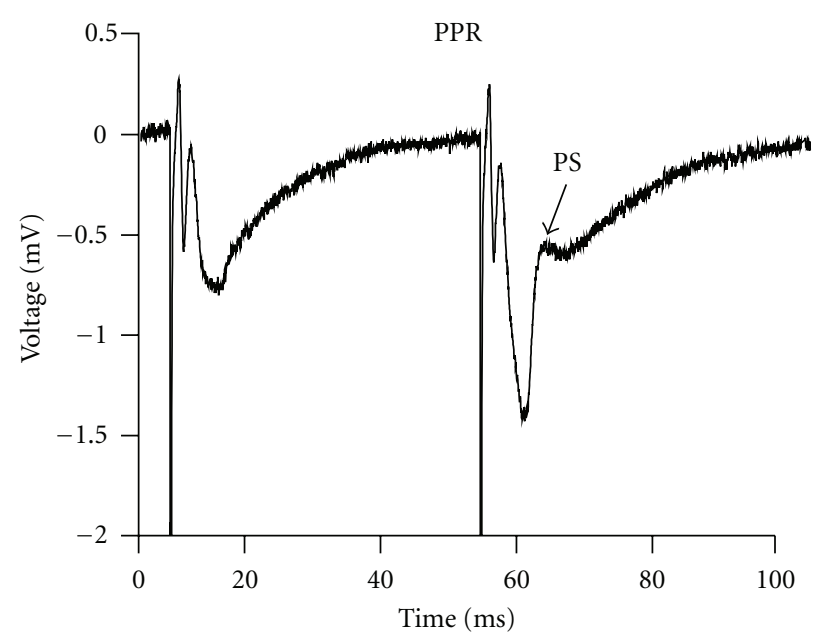

(b)

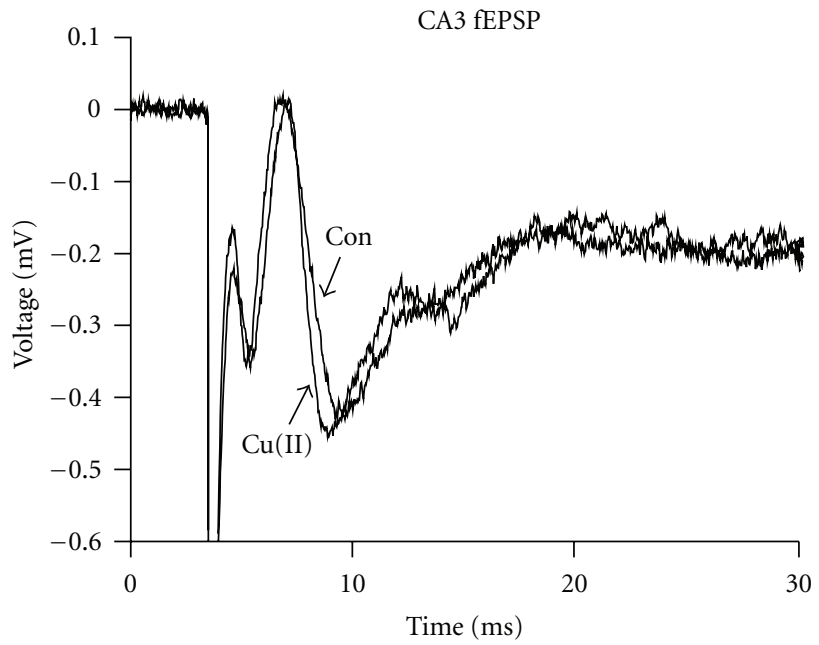

(d)

FIGURE 1: Electrophysiological recording in the mouse hippocampal slice. (a) In the CA1 region, the stimulating electrode (black circle) and the recording electrode (black arrow) were placed in the stratum radiatum. In the CA3 region, the mossy fibers were stimulated (white circle), and recording was done in the stratum lucidum (white arrow). (b) A representative trace from one brain slice showing how a pairedpulse test appeared at the stimulus intensity chosen for recording. (c) and (d) The average of the slopes of the fEPSPs taken 30 seconds before the tetanus was not changed by copper in either the CA1 or CA3 regions ( $n=8$, data not shown). Representative traces from an interleaved experiment are shown.

blocked it (Figures 2(d) and 2(e)). In addition, PTP was statistically significantly reduced by copper in the CA3 region (Figure 2(f)). To the best of our knowledge, these results are the first reported demonstrating that copper inhibits NMDA receptor-independent LTP in the CA3 region of the hippocampus.

Since LTP in the mossy fiber to CA3 cell synapse is thought to be expressed through a presynaptic mechanism [22-25], we were interested in more deeply investigating potential copper-dependent changes in presynaptic plasticity which might occur before and after the induction of LTP. Therefore, we measured the PPR in the presence and absence of $5 \mu \mathrm{M} \mathrm{CuCl}_{2}$. Confirming previous work, copper did not affect the baseline PPR in the CAl region (Figure 3(a), left panel), and, in the CA3 region, copper only slightly increased it (Figure 3(a), right panel) [15]. With picrotoxin, which as noted was necessary to achieve LTP in the CA3 region, paired-pulse facilitation was converted to paired-pulse depression (Figure 4). To the best of our knowledge, this lack of an effect of copper on the baseline PPR in the CA3 region has not been reported.

Next, we measured the PPR one hour after inducing LTP in the CA1 and CA3 regions and found that the PPR was significantly enhanced in the presence of copper in the CA1 (Figure 3(a), left panel) but significantly decreased in the CA3 region (Figure 3(a), right panel). To determine whether this effect on the PPR was dependent upon LTP and not simply a result of extended exposure to copper, we incubated the slices for 90 minutes in copper without the LTP-inducing high-frequency stimulus, after which there was no change in 


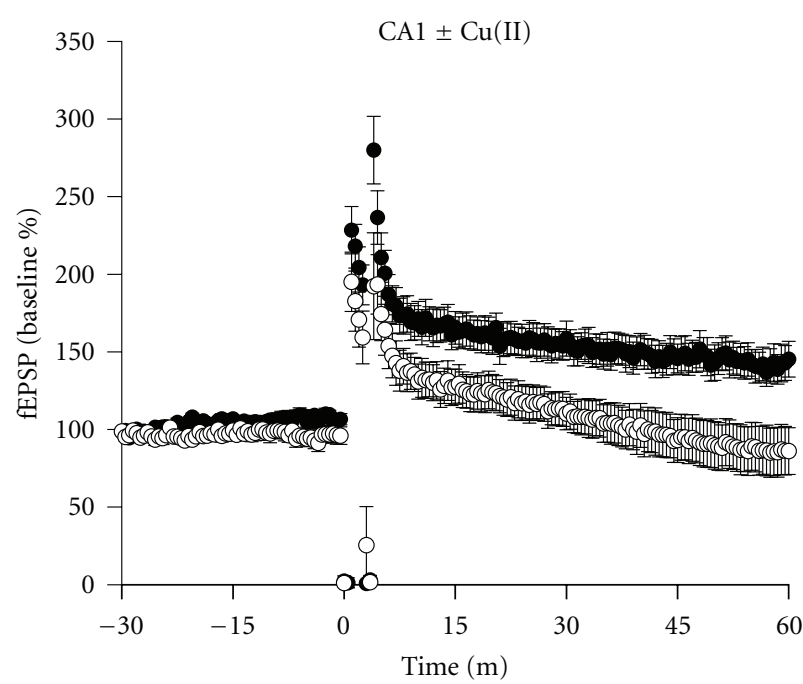

(a)

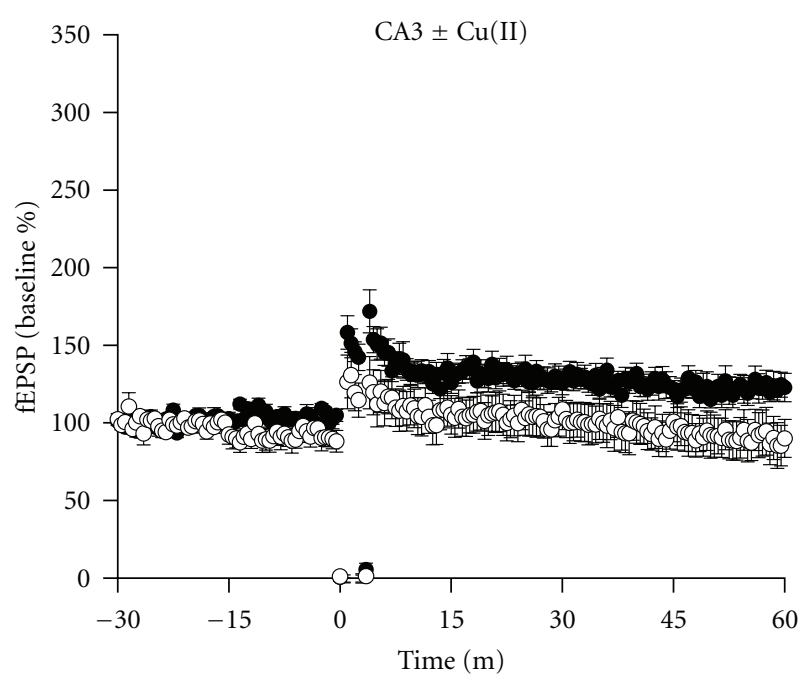

(d)

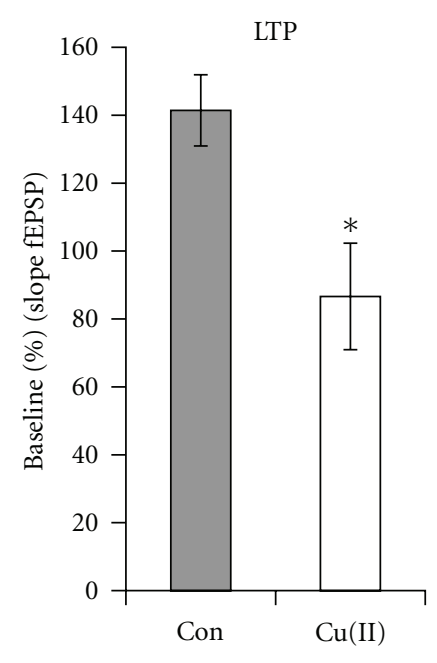

(b)

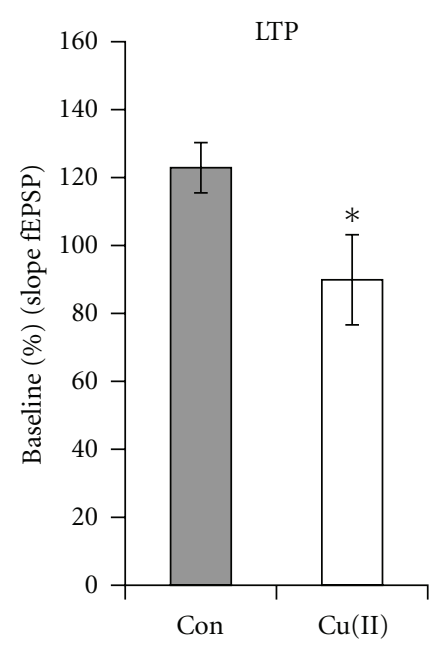

(e)

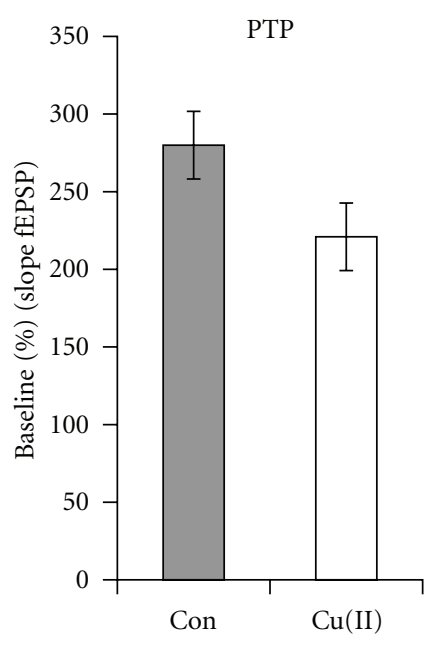

(c)

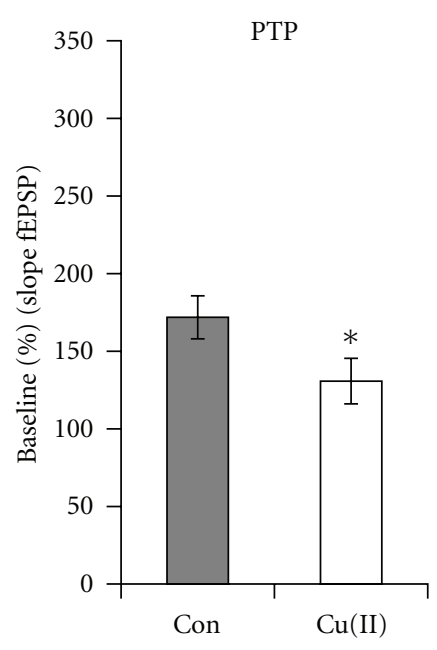

(f)

FIGURE 2: Copper inhibited LTP in the CA1 and CA3 regions of mouse hippocampal slices. (a) In the CA1 region, compared to control slices (black circles), LTP was inhibited by copper (open circles). (b) The average of the fEPSP slopes taken one hour after tetanus was significantly decreased from $141.4 \pm 10.5 \%$ to $86.6 \pm 15.7 \%$ in copper-treated slices $(P=0.034, n=8)$. (c) In the CA1 region, the peak PTP was reduced from $280.0 \pm 21.8 \%$ to $220.9 \pm 21.8 \%$ in copper-treated slices $(P=0.069, n=8)$. (d) Copper-inhibited LTP in the CA3 region of the mouse hippocampus, control groups are indicated by black circles and copper-treated groups are indicated by open circles. (e) The average fEPSP in the CA3 region measured one hour after tetanus was significantly decreased from $122.9 \pm 7.4 \%$ to $89.9 \pm 13.3 \%$ in copper-treated slices $(P=0.016, n=8)$. (f) In the CA3 region, the peak PTP was significantly reduced from $171.8 \pm 13.9 \%$ to $130.8 \pm 14.7 \%$ in copper-treated slices $(P=0.039, n=8)$.

the PPR in either hippocampal region (Figure 3(b)). Combined, our results in both regions indicated that LTP caused the appearance of a presynaptic sensitivity to copper which was expressed as a modulation of the PPRs. These results extend the findings of Goldschmith et al. (2005) who showed that rats which had chronically ingested copper displayed changes in the PPR following the expression of LTP in the CA1 region [18].

The effect of copper on PPRs in the CA1 region appeared gradually, as evident when paired-pulse tests were done at intervals preceding and following the tetanus (Figure 5). Over this time course, we found that the enhancement of the PPR matured and became statistically significant only later, at 60 minutes after tetanus, during the maintenance phase of LTP.

While the effects of copper on synaptic plasticity were clearly NMDA receptor independent in the CA3 region, the NMDA receptor dependence is not as easy to ascertain in the CA1 region. Therefore, to more deeply investigate the potential role of NMDA receptors in the CA1 region, we tested 


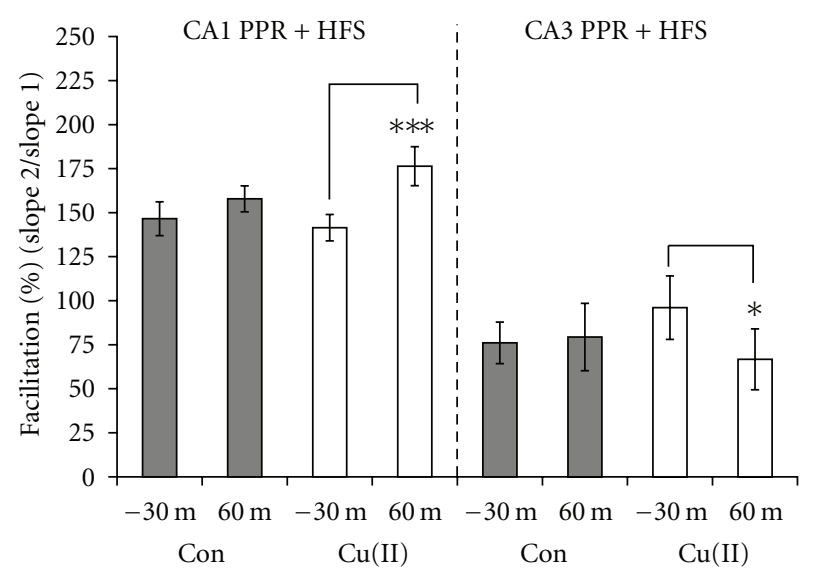

(a)

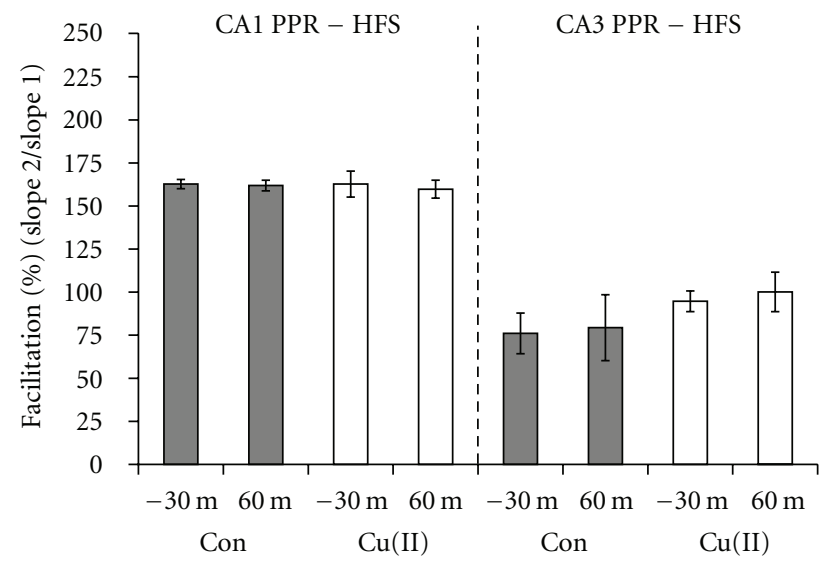

(b)

FIgURe 3: Modulation of the PPR by copper in the CA1 and CA3 regions was dependent on LTP. (a) The average of the PPRs measured 30 minutes before tetanizing the slices was not different in copper-treated (white bars), compared to control slices (gray bars) in either the CA1 or CA3 region. Also, the PPRs in control slices did not change after LTP in either brain region. However, after LTP, copper-treated slices showed a $34.9 \%$ enhancement of the PPR in the CA1 region $(P<0.001, n=8)$ and a $29.3 \%$ decrease in the PPR in the CA3 region $(P=0.05$, $n=8$ ). (b) Without the HFS, there was no significant change in the PPRs compared between control and copper-treated slices in either the CA1 or CA3 region.

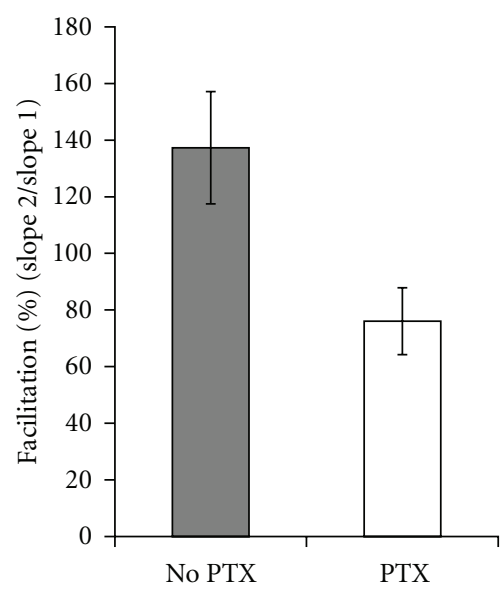

Figure 4: Paired-pulse facilitation was converted to paired-pulse depression by picrotoxin in the CA3 region. The average PPR without picrotoxin was $137.3 \pm 19.8 \%(n=4)$, but the average PPR with picrotoxin was $76.1 \% \pm 11.8 \%(n=8)$.

whether the zinc modulatory site of the NMDA receptor was a target for copper [26]. Similar to the work of others who have shown that zinc modulates LTP in the CA1 region, LTP was significantly inhibited by $5 \mu \mathrm{M} \mathrm{ZnCl}_{2}$, just as with copper at an equivalent concentration (Figures 6(a) and $6(\mathrm{~b}))[27,28]$. Thus, zinc mimicked the inhibition of LTP by copper. In contrast, zinc and copper had divergent effects on the LTP-dependent changes in the PPR (Figure 6(c)), as there was no significant difference in the PPR before as compared to after LTP in zinc-treated groups. Therefore, copper/LTP-dependent modulation of the PPR in the CA1 region was unique to copper and could not be mimicked by zinc, suggesting the existence of separate mechanisms for the

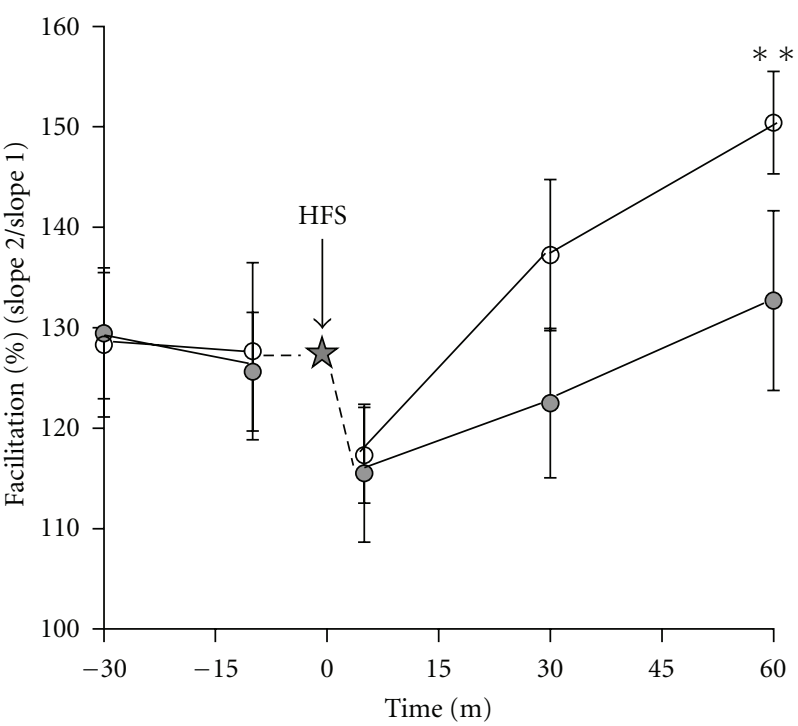

FIGURE 5: Copper gradually enhanced the PPR after LTP in the CA1 region. Paired-pulse tests were done at intervals before and after the HFS tetanus (star). Prior to the tetanus, the PPR was not significantly different between control slices (filled circles) and coppertreated slices (open circles). Five minutes after the HFS, there was a decrease in the PPR. The difference in the percent facilitation became statistically significant 60 minutes after the tetanus, at which point the average PPR of the copper group was $150.4 \pm 5.1 \%$ as compared to $132.7 \pm 8.9 \%$ in the control group $(P=0.007, n=5)$.

inhibition of LTP and LTP-dependent modulation of PPRs for the two ions.

Next we examined whether AMPA receptor function might be part of the mechanism by which copper inhibited LTP and enhanced the PPR after LTP in the CA1 region. To 


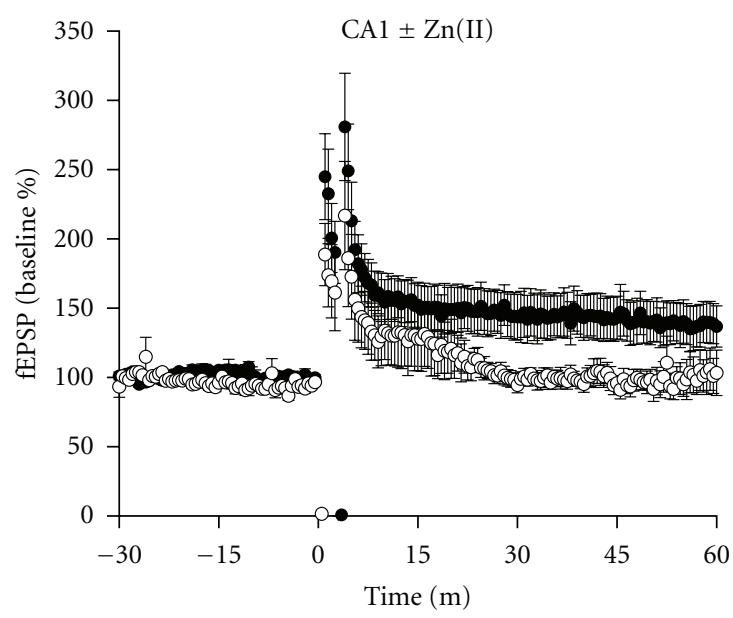

(a)

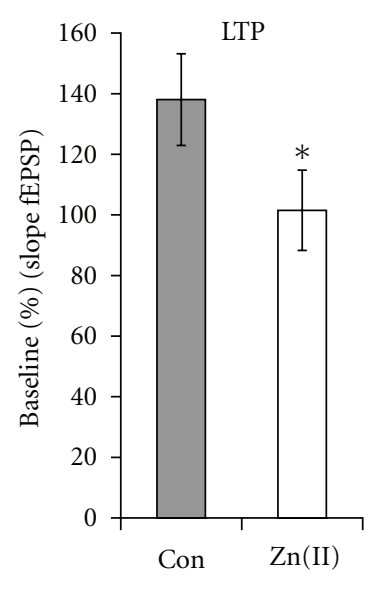

(b)

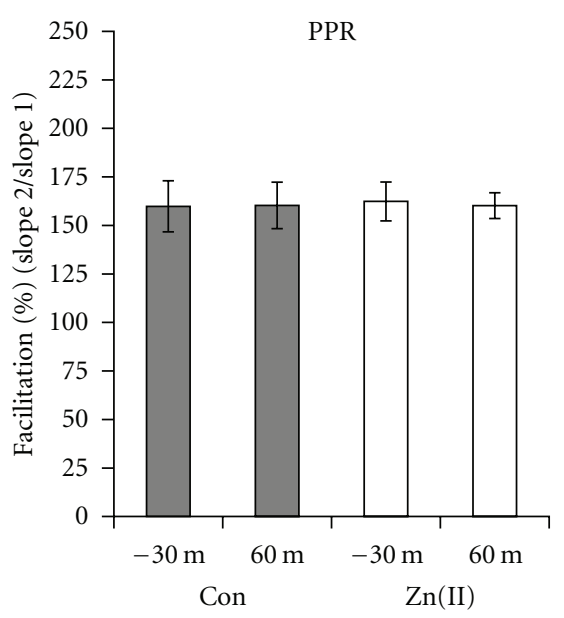

(c)

FIGURE 6: Zinc blocked LTP but did not change the PPR after LTP in the CA1 region. (a) LTP was present in control slices (filled circles) but was blocked by $5 \mu \mathrm{M} \mathrm{ZnCl}_{2}$ (open circles). (b) The magnitude of the LTPs averaged one hour after the tetanus was reduced from $138.0 \pm 15.1 \%$ to $101.5 \pm 13.2 \%$ in zinc-treated slices $(P=0.013, n=8)$. (c) The PPR after the expression of LTP was not affected by zinc (open circles). All slices were tetanized at $t=0 \mathrm{~m}$ in this experiment.

do this, we treated brain slices with $100 \mu \mathrm{M}$ CTZ to inhibit AMPA receptor desensitization. We found that CTZ alone did not alter LTP, consistent with previously published results (Figures 7(a) and 7(b)) [29]. However, CTZ enhanced the inhibitory effect of copper on LTP. The enhancement was synergistic since the effect of both copper and CTZ together reduced the LTP by $71.4 \%$ while their individual effects added together only reduced it by $43.0 \%$ (Figure $7($ b) ). Presynaptically, CTZ completely blocked, and even slightly reversed, copper/LTP-dependent enhancement of the PPR without significantly altering the baseline PPRs, suggesting that AMPA receptors might be responsible for the presynaptic effects of copper (Figure 7(c)). However, consistent with previous reports, CTZ alone also significantly reduced the PPR after a 90-minute incubation; therefore, its block of the presynaptic effects was not necessarily LTP dependent and instead may have represented an occlusion of the presynaptic effect (Figure 7(c)) [30, 31].

\section{Discussion}

4.1. Copper Inhibits NMDA Receptor-Independent LTP. Inhibition of LTP by copper has been well established in the CA1 region of the hippocampus, but the mechanism remains poorly characterized. It has been suggested that copper inhibits LTP mainly through a postsynaptic interaction with NMDA receptors; however, many other important effectors of synaptic plasticity are known targets of copper which could contribute to the mechanism $[15,18-20]$. To clarify this possibility, we showed here for the first time that copper can inhibit LTP independent of NMDA receptors in the CA3 region of the mouse hippocampus. NMDA receptor independence was ensured by the use of $10 \mu \mathrm{M}$ MK-801, an NMDA receptor antagonist with an $\mathrm{IC}_{50}$ of $0.13 \mu \mathrm{M}$, and stimulation of the mossy fiber pathway with the recording electrode placed in the stratum lucidum; a placement that has been shown to isolate NMDA receptor-independent LTP in the CA3 region $[23,32]$.

The inhibition of LTP by copper in the CA3 region of the hippocampus indicated a possible presynaptic mechanism for copper, as LTP in this region of the brain is thought to be expressed through a presynaptic mechanism [22-25]. Since posttetanic potentiation (PTP) is also a presynaptic phenomenon, this was further supported by our observations that copper reduced PTP [33]. Potential non-NMDA receptor presynaptic targets for copper could include the glutamate release machinery since increased release is a major mechanism behind LTP in the CA3 region [25]. While it has not been replicated in intact cells with physiological concentrations of copper, this idea is further supported by studies showing that copper enhances vesicular binding to membrane fractions [34]. Thus, one could speculate that an interaction between copper- and zinc-binding domains on proteins that regulate vesicular release, such as rab3A, could be a specific target of copper $[35,36]$. It is also possible that copper may be interacting with presynaptic voltage-gated calcium channels, GABA receptors, Kainate, or AMPA receptors, as each of these has a role in regulating neurotransmitter release $[12,24,37,38]$.

CA3 neurons are strongly inhibited by GABAergic pathways, and it was necessary to use picrotoxin, a $G_{A B A}$ receptor inhibitor, in order to obtain LTP in the CA3 region in our studies. GABA receptors serve a complex role in LTP, and there is contradiction in the literature regarding it. For example, in the CA3 region, picrotoxin facilitates LTP, whereas gabazine, used to block presynaptic $\mathrm{GABA}_{\mathrm{A}}$ receptors, inhibits it [37,39]. Additionally, copper was shown to inhibit GABA receptors in whole-cell patch clamp studies but acted as an agonist in brain slices [11, 14]. Therefore, the use of picrotoxin in our studies, although necessary, added 


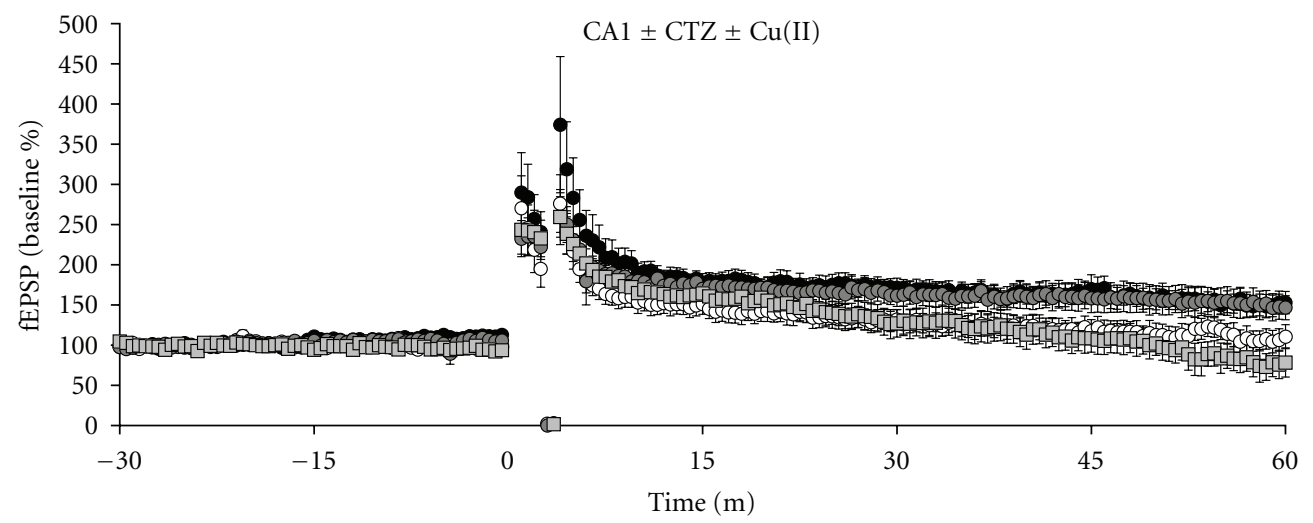

(a)

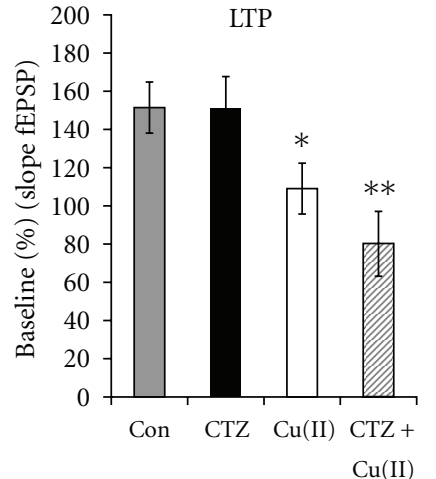

(b)

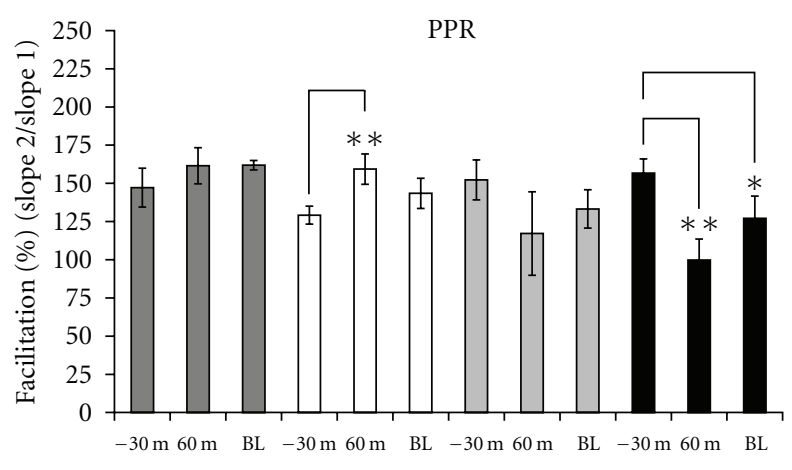

Con

$\mathrm{CTZ}+\mathrm{Cu}(\mathrm{II})$

CTZ

(c)

FIgURE 7: CTZ modulated the effect of copper on synaptic plasticity in the CA1 region. (a) Slices treated with CTZ (black circles) and control slices (gray circles) exhibited identical LTP, but LTP was inhibited by copper (open circles) and by copper combined with CTZ (gray squares). (b) The level of LTP was $151.5 \pm 13.4 \%$ in control slices (gray bar) $(n=8)$ and $151.0 \pm 16.7 \%$ in CTZ-treated slices (black bar) $(n=8)$. Copper reduced the LTP to $109.0 \pm 13.3 \%$ (white bar), and LTP was further reduced to $80.1 \pm 17.0 \%$ in slices treated with copper and CTZ (striped bar) $(n=8)$. (c) There was no significant difference among the PPRs at 30 minutes prior to the tetanus across groups. At 60 minutes after tetanus, there was no change in the PPR in the control group, a significant enhancement in the PPR in the copper group $(P=0.028$, $n=7)$, no significant change in the PPR in the CTZ + copper group, and a significant decrease in the PPR in the CTZ group $(P=0.006$, $n=7)$. The baseline (BL) PPRs measured after 90 minutes without a tetanus was decreased from $152.2 \pm 13.1 \%$ at 30 minutes prior to the tetanus to $133.3 \pm 12.5 \%$ in slices treated with $\mathrm{CTZ}(P=0.018, n=7)$. The BL PPRs did not vary among the other groups.

complexity to interpreting the potential mechanism of the inhibition of LTP by copper in this brain region. Regardless, the major result of this work was the complete inhibition of NMDA receptor-independent LTP in the CA3 region by copper.

NMDA receptors are known to be inhibited by zinc, and, since copper and zinc share similar biological functions in the nervous system, presumably due to their similar valence, size, and charge, we postulated that copper interacts with this site to inhibit LTP $[10,40-42]$. In the CA1 region, we showed that zinc inhibited LTP just as copper did, suggesting that copper and zinc may share this mechanism. However, contrary to our results, it was previously demonstrated that zinc positively modulates LTP [43]. This discrepancy with our work could be explained by differences in the stimulus pattern used to induce LTP, as we used four trains at $100 \mathrm{~Hz}$ to induce our LTP, whereas one train of $10-100 \mathrm{~Hz}$ was used in the previous study [43]. This explanation was further supported in a follow-up publication showing that LTP in brain slices tetanized six times at $100 \mathrm{~Hz}$ was not potentiated by zinc, whereas those tetanized once were potentiated [28]. Thus, increasing the stimulus, strength appears to reduce or, in our case reverse, the enhancing effects that zinc exerts on LTP. This is also consistent with studies showing that the LTP-inducing stimulus pattern effects whether the coppersensitive $\mathrm{A} \beta$ peptide of Alzheimer's disease can inhibit LTP [21]. Finally, it should be noted that we performed our studies at room temperature, whereas those which showed that zinc increases LTP were performed at $26-27^{\circ} \mathrm{C}$, and this may have contributed in part to the difference $[28,43]$. Overall, our work suggested that copper interacts with the zinc-modulatory site on the NMDA receptor as a potential part of the mechanism for inhibition of LTP by copper in the CA1 region of the hippocampus.

AMPA receptors are a major effector of synaptic plasticity in the hippocampus and are known to be functionally inhibited by micromolar concentrations of copper with kinetics indicative of two binding sites with differing sensitivities to 
copper $[12,27]$. Therefore, we hypothesized that some aspect of AMPA receptor function might explain the inhibition of LTP by copper in the CA1 region. To investigate this, we treated our slices with cyclothiazide (CTZ), an inhibitor of AMPA receptor desensitization, and measured LTP in our system. Consistent with previous studies, CTZ did not significantly affect or mimic the effect of copper on LTP in these experiments [29]. We interpret this to mean that inhibition of LTP by copper was probably not through a mechanism involving desensitization of AMPA receptors. However, because CTZ was synergistic with copper in enhancing the inhibition of LTP, it was suggested that copper might affect it by a mechanism that includes a component of AMPA receptor function. For example, binding to CTZ might induce a conformational change in the AMPA receptor that increases an interaction with copper.

\subsection{Copper Affects Presynaptic Plasticity in an LTP-Dependent} Manner. The second major finding of the work presented here is that copper modulated the PPR, a measure of the probability of neurotransmitter release $\left(P_{r}\right)$, in a strictly LTPdependent manner in both the CA1 and CA3 regions. These results were consistent with a previously published report showing that the PPR is changed in the CA1 region following LTP in rats that had chronically consumed copper in their drinking water [18]. Our results extended these findings to the CA3 region and suggested that LTP induced a change in the presynaptic terminal that creates or unmasks a sensitivity to copper.

The failure of zinc to affect the PPR after LTP in our experiments in the same way as copper ruled out a mechanism such as an interaction between copper and the zincbinding domain of presynaptic NMDA receptors. Thus, our studies with zinc indicated that inhibition of LTP and LTPdependent modulation of the PPR were not expressed by the same mechanism and supported the idea that copper influences synaptic plasticity through multiple mechanisms.

Our result showing that CTZ, a compound that blocks AMPA receptor desensitization, completely blocked the effect of copper on the LTP-dependent enhancement of the PPR in the CA1 region suggested that the presynaptic AMPA receptors which regulate neurotransmitter release may be a primary target of copper. However, because CTZ also reduced the PPR in the absence of copper, the apparent block could have resulted from blocking AMPA receptor desensitization to increase the $P_{r}$, decrease the PPR, and occlude the copperdependent increase in the PPR $[30,31]$. On the other hand, CTZ and copper could exhibit opposing effects through uniquely different interactions with AMPA receptors. Such opposing effects would be consistent with reports that CTZ enhances AMPA receptor function by increasing AMPA receptor currents and lengthening single-channel opening, while copper inhibits AMPA receptor function by decreasing these currents $[12,44]$.

An additional aspect regarding the modulation of PPF after LTP was the observation that, in the CA1 region, the PPR was increased by copper, consistent with a mechanism whereby the $P_{r}$ was decreased. However, after LTP was expressed in the CA3 region, the PPR was decreased, consistent with a mechanism involving an increase in the $P_{r}$. If PTX, used in the CA3 region, enhanced the $P_{r}$ by blocking an antagonistic pathway, this could help explain our result. However, presynaptic $\mathrm{GABA}_{\mathrm{A}}$ receptors facilitate neurotransmitter release, and their inhibition blocks LTP in the CA3 region, so presynaptic $\mathrm{GABA}_{\mathrm{A}}$ receptors may not have been involved [37]. The $P_{r}$ is also influenced by the relative sizes of the readily releasable and reserve pools of neurotransmitter, with small releasable pools and large reserve pools supporting paired-pulse facilitation and the converse supporting paired-pulse depression [45]. Thus, the apparent increase in $P_{r}$ which we observed as a decreased PPR could have resulted from an increase in the readily releasable pool. This would be consistent with a copperdependent enhancement of vesicular binding to the presynaptic terminal as has been shown in isolated brain synaptic vesicles [34]. Overall, our data clearly shows a copperdependent modulation of the PPR after LTP in both the CA3 and CA1 hippocampal areas and strongly points to a role for copper in modulating presynaptic plasticity during LTP.

Combined, our work with LTP and short-term presynaptic plasticity suggests potential members of a copper interactome that could include both pre- and postsynaptic NMDA receptors, pre-synaptic AMPA, GABA receptors, Rab GTPases, and voltage-gated calcium channels. In addition, the Alzheimer's disease $\mathrm{A} \beta$ peptide, the prion protein $\left(\operatorname{PrP}^{\mathrm{c}}\right)$, as well as $\mathrm{Cu} / \mathrm{Zn}$-superoxide dismutase, are each regulated by binding to copper, have well documented roles in modulating synaptic plasticity, and could be part of a set of copperinteracting proteins that influence the deterioration of learning and memory in neurodegenerative diseases [4649]. Indeed, copper-based therapies based on an interaction between copper and the Alzheimer's disease $\mathrm{A} \beta$ protein are currently in development for the treatment of Alzheimer's disease and show promise for treating prion diseases [4952]. Thus, the work presented here makes a relevant contribution to our understanding of the mechanism by which copper affects synaptic plasticity and points to its presynaptic involvement in the etiology and treatment of copperdependent neurodegenerative disorders.

\section{Conclusions}

We have shown that copper inhibited NMDA receptorindependent LTP in the CA3 region of the mouse hippocampus. Copper had interactions with synaptic plasticity at a presynaptic level, as indicated by our finding that copper significantly enhanced the PPR in the CA1 region and decreased the PPR in the CA3 region in an LTP-dependent manner. In further support of this, copper reduced PTP in the CA1 region and CA3 regions. Thus, LTP caused the appearance of a copper-sensitive factor which modulated the PPR.

\section{Competing Interests}

The author has declared that no competing interests exist. 


\section{Acknowledgments}

The authors would like to thank the National Institute of Health Bridges to the Doctorate Program for their support (Grant no. 1 R25 GM080198-01), Professor L. Donald Partridge for his consultations and the undergraduate student Elizabeth Hahnenberger for her assistance in the lab. This work was funded by Colorado State University-Pueblo.

\section{References}

[1] K. J. Barnham and A. I. Bush, "Metals in Alzheimer's and Parkinson's diseases," Current Opinion in Chemical Biology, vol. 12, no. 2, pp. 222-228, 2008.

[2] S. Lutsenko, A. Bhattacharjee, and A. L. Hubbard, "Copper handling machinery of the brain," Metallomics, vol. 2, no. 9, pp. 596-608, 2010.

[3] Y. H. Hung, A. I. Bush, and R. A. Cherny, "Copper in the brain and Alzheimer's disease," Journal of Biological Inorganic Chemistry, vol. 15, no. 1, pp. 61-76, 2010.

[4] D. Strausak, J. F. B. Mercer, H. H. Dieter, W. Stremmel, and G. Multhaup, "Copper in disorders with neurological symptoms: Alzheimer's, Menkes, and Wilson diseases," Brain Research Bulletin, vol. 55, no. 2, pp. 175-185, 2001.

[5] J. H. Viles, M. Klewpatinond, and R. C. Nadal, "Copper and the structural biology of the prion protein," Biochemical Society Transactions, vol. 36, no. 6, pp. 1288-1292, 2008.

[6] J. Kardos, I. Kovacs, F. Hajos, M. Kalman, and M. Simonyi, "Nerve endings from rat brain tissue release copper upon depolarization. A possible role in regulating neuronal excitability," Neuroscience Letters, vol. 103, no. 2, pp. 139-144, 1989.

[7] A. R. White and R. Cappai, "Neurotoxicity from glutathione depletion is dependent on extracellular trace copper," Journal of Neuroscience Research, vol. 71, no. 6, pp. 889-897, 2003.

[8] A. Mathie, G. L. Sutton, C. E. Clarke, and E. L. Veale, "Zinc and copper: pharmacological probes and endogenous modulators of neuronal excitability," Pharmacology and Therapeutics, vol. 111, no. 3, pp. 567-583, 2006.

[9] T. Narahashi, J. Y. Ma, O. Arakawa, E. Reuveny, and M. Nakahiro, "GABA receptor-channel complex as a target site of mercury, copper, zinc, and lanthanides," Cellular and Molecular Neurobiology, vol. 14, no. 6, pp. 599-621, 1994.

[10] I. N. Sharonova, V. S. Vorobjev, and H. L. Haas, "Interaction between copper and zinc at $\operatorname{GABA}(\mathrm{A})$ receptors in acutely isolated cerebellar Purkinje cells of the rat," British Journal of Pharmacology, vol. 130, no. 4, pp. 851-856, 2000.

[11] J. Leiva, M. Palestini, M. Tetas, and J. López, "Copper sensitivity in dorsal hippocampus slices," Archives Italiennes de Biologie, vol. 138, no. 2, pp. 175-184, 2000.

[12] T. Weiser and M. Wienrich, "The effects of copper ions on glutamate receptors in cultured rat cortical neurons," Brain Research, vol. 742, no. 1-2, pp. 211-218, 1996.

[13] V. Vlachová, "Copper modulation of NMDA responses in mouse and rat cultured hippocampal neurons," European Journal of Neuroscience, vol. 8, no. 11, pp. 2257-2264, 1996.

[14] I. N. Sharonova, V. S. Vorobjev, and H. L. Haas, "High-affinity copper block of GABAA receptor-mediated currents in acutely isolated cerebellar Purkinje cells of the rat," European Journal of Neuroscience, vol. 10, no. 2, pp. 522-528, 1998.

[15] N. Doreulee, Y. Yanovsky, and H. L. Haas, "Suppression of long-term potentiation in hippocampal slices by copper," Hippocampus, vol. 7, no. 6, pp. 666-669, 1997.
[16] R. A. Nicoll and R. C. Malenka, "Expression mechanisms underlying NMDA receptor-dependent long-term potentiation," Annals of the New York Academy of Sciences, vol. 868, pp. 515-525, 1999.

[17] T. V. P. Bliss and G. L. Collingridge, "A synaptic model of memory: long-term potentiation in the hippocampus," $\mathrm{Na}$ ture, vol. 361, no. 6407, pp. 31-39, 1993.

[18] A. Goldschmith, C. Infante, J. Leiva, E. Motles, and M. Palestini, "Interference of chronically ingested copper in longterm potentiation (LTP) of rat hippocampus," Brain Research, vol. 1056, no. 2, pp. 176-182, 2005.

[19] J. Leiva, M. Palestini, C. Infante, A. Goldschmidt, and E. Motles, "Copper suppresses hippocampus LTP in the rat, but does not alter learning or memory in the morris water maze," Brain Research, vol. 1256, pp. 69-75, 2009.

[20] J. Leiva, P. Gaete, and M. Palestini, "Copper interaction on the long-term potentiation," Archives Italiennes de Biologie, vol. 141, no. 4, pp. 149-155, 2003.

[21] J. P. Smith, V. Lal, D. Bowser, R. Cappai, C. L. Masters, and G. D. Ciccotosto, "Stimulus pattern dependence of the Alzheimer's disease amyloid- $\beta 42$ peptide's inhibition of long term potentiation in mouse hippocampal slices," Brain Research, vol. 1269, pp. 176-184, 2009.

[22] P. E. Castillo, M. G. Weisskopf, and R. A. Nicoll, "The role of $\mathrm{Ca}^{2+}$ channels in hippocampal mossy fiber synaptic transmission and long-term potentiation," Neuron, vol. 12, no. 2, pp. 261-269, 1994.

[23] E. W. Harris and C. W. Cotman, "Long-term potentiation of guinea pig mossy fiber responses is not blocked by N-methyl D-aspartate antagonists," Neuroscience Letters, vol. 70, no. 1, pp. 132-137, 1986.

[24] Z. A. Bortolotto, S. Lauri, J. T. R. Isaac, and G. L. Collingridge, "Kainate receptors and the induction of mossy fibre long-term potentiation," Philosophical Transactions of the Royal Society B, vol. 358, no. 1432, pp. 657-666, 2003.

[25] Y. Kawamura, S. Manita, T. Nakamura, M. Inoue, Y. Kudo, and H. Miyakawa, "Glutamate release increases during mossy-CA3 LTP but not during Schaffer-CA1 LTP," European Journal of Neuroscience, vol. 19, no. 6, pp. 1591-1600, 2004.

[26] J. Rachline, F. Perin-Dureau, A. Le Goff, J. Neyton, and P. Paoletti, "The micromolar zinc-binding domain on the NMDA receptor subunit NR2B," The Journal of Neuroscience, vol. 25, no. 2, pp. 308-317, 2005.

[27] R. A. Lorca, C. Rozas, S. Loyola et al., "Zinc enhances longterm potentiation through $\mathrm{P} 2 \mathrm{X}$ receptor modulation in the hippocampal CA1 region," European Journal of Neuroscience, vol. 33, no. 7, pp. 1175-1185, 2011.

[28] A. Takeda, H. Iwaki, M. Ando, K. Itagaki, M. Suzuki, and N. Oku, "Zinc differentially acts on components of long-term potentiation at hippocampal CA1 synapses," Brain Research, vol. 1323, pp. 59-64, 2010.

[29] G. Rammes, H. U. Zeilhofer, G. L. Collingridge, C. G. Parsons, and D. Swandulla, "Expression of early hippocampal CA1 LTP does not lead to changes in AMPA-EPSC kinetics or sensitivity to cyclothiazide," Pflugers Archiv European Journal of Physiology, vol. 437, no. 2, pp. 191-196, 1999.

[30] J. S. Diamond and C. E. Jahr, "Asynchronous release of synaptic vesicles determines the time course of the AMPA receptormediated EPSC," Neuron, vol. 15, no. 5, pp. 1097-1107, 1995.

[31] S. Gasparini, C. Saviane, L. L. Voronin, and E. Cherubini, "Silent synapses in the developing hippocampus: lack of functional AMPA receptors or low probability of glutamate release?" Proceedings of the National Academy of Sciences of the United States of America, vol. 97, no. 17, pp. 9741-9746, 2000. 
[32] E. J. Coan, W. Saywood, and G. L. Collingridge, "MK-801 blocks NMDA receptor-mediated synaptic transmission and long term potentiation in rat hippocampal slices," Neuroscience Letters, vol. 80, no. 1, pp. 111-114, 1987.

[33] V. Balakrishnan, G. Srinivasan, and H. Von Gersdorff, "Posttetanic potentiation involves the presynaptic binding of calcium to calmodulin," Journal of General Physiology, vol. 136, no. 3, pp. 243-245, 2010.

[34] W. Hoss and M. Formaniak, "Enhancement of synaptic vesicle attachment to the plasma membrane fraction by copper," Neurochemical Research, vol. 5, no. 7, pp. 795-803, 1980.

[35] G. Lonart, R. Janz, K. M. Johnson, and T. C. Südhof, "Mechanism of action of rab3A in mossy fiber LTP," Neuron, vol. 21, no. 5, pp. 1141-1150, 1998.

[36] A. Mishra, S. Eathiraj, S. Corvera, and D. G. Lambright, "Structural basis for Rab GTPase recognition and endosome tethering by the $\mathrm{C}_{2} \mathrm{H}_{2}$ zinc finger of Early Endosomal Autoantigen 1 (EEA1)," Proceedings of the National Academy of Sciences of the United States of America, vol. 107, no. 24, pp. 10866-10871, 2010.

[37] A. Ruiz, E. Campanac, R. S. Scott, D. A. Rusakov, and D. M. Kullmann, "Presynaptic $\mathrm{GABA}_{A}$ receptors enhance transmission and LTP induction at hippocampal mossy fiber synapses," Nature Neuroscience, vol. 13, no. 4, pp. 431-438, 2010.

[38] U. Schenk and M. Matteoli, "Presynaptic AMPA receptors: more than just ion channels?" Biology of the Cell, vol. 96, no. 4, pp. 257-260, 2004.

[39] D. Johnston, S. Williams, D. Jaffe, and R. Gray, "NMDAreceptor-independent long-term potentiation," Annual Review of Physiology, vol. 54, pp. 489-505, 1992.

[40] P. Paoletti, P. Ascher, and J. Neyton, "High-affinity zinc inhibition of NMDA NR1-NR2A receptors," The Journal of Neuroscience, vol. 17, no. 15, pp. 5711-5725, 1997.

[41] J. P. Huidobro-Toro, R. A. Lorca, and C. Coddou, "Trace metals in the brain: allosteric modulators of ligand-gated receptor channels, the case of ATP-gated P2X receptors," European Biophysics Journal, vol. 37, no. 3, pp. 301-314, 2008.

[42] C. J. Frederickson, J. Y. Koh, and A. I. Bush, "The neurobiology of zinc in health and disease," Nature Reviews Neuroscience, vol. 6, no. 6, pp. 449-462, 2005.

[43] A. Takeda, S. Fuke, M. Ando, and N. Oku, "Positive modulation of long-term potentiation at hippocampal CA1 synapses by low micromolar concentrations of zinc," Neuroscience, vol. 158, no. 2, pp. 585-591, 2009.

[44] S. Fucile, R. Miledi, and F. Eusebi, "Effects of cyclothiazide on GluR1/AMPA receptors," Proceedings of the National Academy of Sciences of the United States of America, vol. 103, no. 8, pp. 2943-2947, 2006.

[45] C. Saviane, L. P. Savtchenko, G. Raffaelli, L. L. Voronin, and E. Cherubini, "Frequency-dependent shift from pairedpulse facilitation to paired-pulse depression at unitary CA3CA3 synapses in the rat hippocampus," Journal of Physiology, vol. 544, part 2, pp. 469-476, 2002.

[46] J. Herms, T. Tings, S. Gall et al., "Evidence of presynaptic location and function of the prion protein," The Journal of Neuroscience, vol. 19, no. 20, pp. 8866-8875, 1999.

[47] M. Kawahara, H. Koyama, T. Nagata, and Y. Sadakane, "Zinc, copper, and carnosine attenuate neurotoxicity of prion fragment PrP106-126," Metallomics, vol. 3, no. 7, pp. 726-734, 2011.

[48] E. Gahtan, J. M. Auerbach, Y. Groner, and M. Segal, "Reversible impairment of long-term potentiation in transgenic Cu/Zn-SOD mice," European Journal of Neuroscience, vol. 10, no. 2, pp. 538-544, 1998.
[49] A. I. Bush and R. E. Tanzi, "Therapeutics for Alzheimer's disease based on the metal hypothesis," Neurotherapeutics, vol. 5, no. 3, pp. 421-432, 2008.

[50] P. A. Adlard, R. A. Cherny, D. I. Finkelstein et al., "Rapid restoration of cognition in Alzheimer's transgenic mice with 8-hydroxy quinoline analogs is associated with decreased interstitial A $\beta$," Neuron, vol. 59, no. 1, pp. 43-55, 2008.

[51] G. D. Ciccotosto, D. J. Tew, S. C. Drew et al., "Stereospecific interactions are necessary for Alzheimer disease amyloid- $\beta$ toxicity," Neurobiology of Aging, vol. 32, no. 2, pp. 235-248, 2011.

[52] E. Jouvin-Marche, V. Attuil-Audenis, C. Aude-Garcia et al., "Overexpression of cellular prion protein induces an antioxidant environment altering T cell development in the thymus," The Journal of Immunology, vol. 176, no. 6, pp. 3490-3497, 2006. 


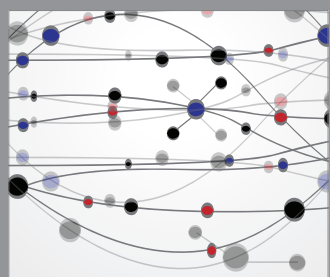

The Scientific World Journal
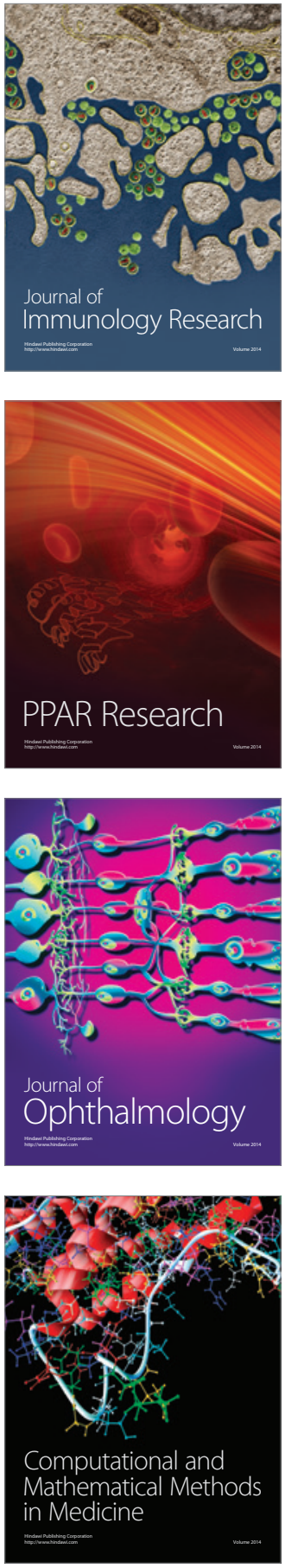

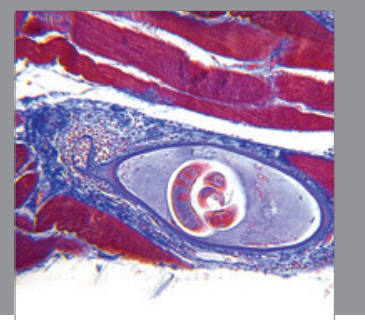

Gastroenterology

Research and Practice
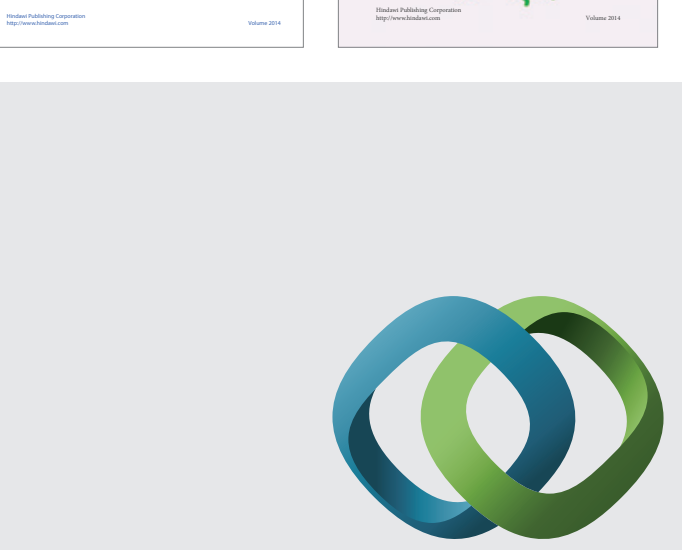

\section{Hindawi}

Submit your manuscripts at

http://www.hindawi.com
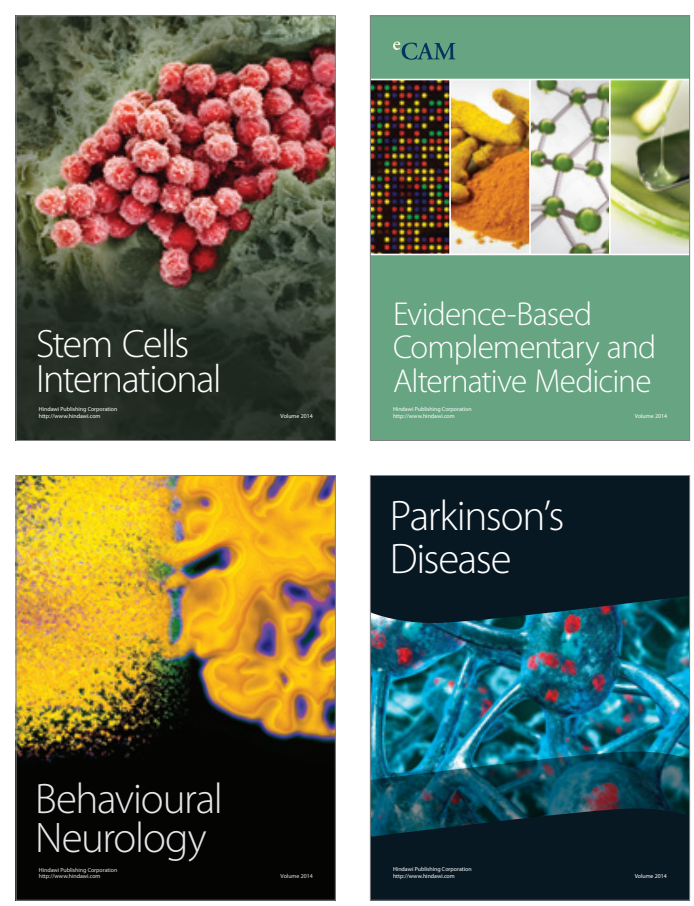

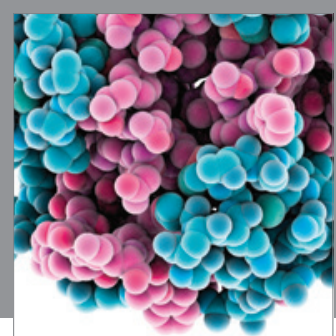

Journal of
Diabetes Research

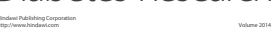

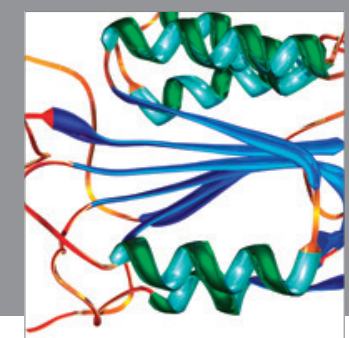

Disease Markers
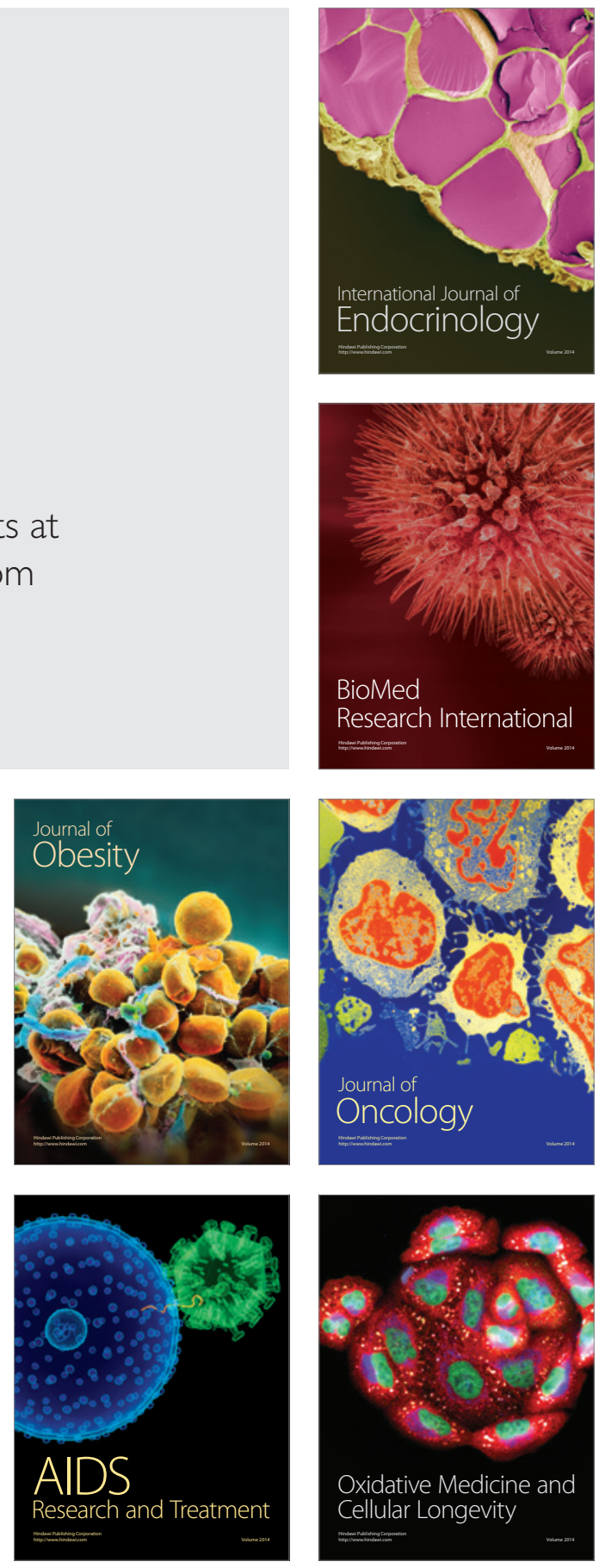